\title{
SPECTRAL-LUMINESCENT PROPERTIES OF CATIONIC INDOTRICARBOCYANINE DYES IN CANCEROUS CELLS AND SOLUTIONS
}

\author{
E. S. Voropai, M. P. Samtsov, ${ }^{*}$ K. N. Kaplevskii,
} A. A. Lugovskii, and E. N. Alexandrova

UDC 535.37

The spectral-luminescent properties of symmetrical indotricarbocyanine dyes with the same cation and different anions $\left(\mathrm{Br}^{-}, \mathrm{BF}_{4}^{-}\right)$in cancerous HeLa cells, an isotonic solution of $\mathrm{NaCl}$, and organic solvents have been investigated. It is shown that when these dyes are present in cells in nontoxic concentrations, they are in a monomeric state, they are localized in the region with a low dielectric permeability, bonded to biological macromolecules, and do not make contact with an aqueous medium. It has been established for the first time that the molecules of the polymeric dyes are present in cells predominantly in the form of contact ion pairs, and in a dye with the $\mathrm{Br}^{-}$anion the presence of free cations or solvately separated ionic pairs is revealed. It is shown that the shift of the ion equilibrium toward contact ion pairs for the dyes in the cells (as compared to the low-polarity organic solvents) can be due to the fairly high concentration of salts in the biosystem.

Keywords: indotricarbocyanine dyes, HeLa cells, ion pairs, electronic absorption and emission spectra, degree of polarization, lifetime and quantum yield of fluorescence.

Introduction. Polymethine dyes (PD), the absorption spectra of which are located in the visible region, are rather widely used in carrying out biological investigations; they serve as probes for determining a transmembrane potential $[1,2]$. Compounds of this class which have an absorption band in the near-IR range have recently been under study from the viewpoint of the prospects for their use in medicine. The coincidence of the absorption and emission spectra of such PD with the transparency window of biological tissues and also complexing with biological macromolecules raises the possibility of their wider use as fluorescent different-purpose probes [3, 4]. Moreover, cationic polymeric dyes are considered as a basis of preparations for photochemotherapy and diagnostics of cancer [5-12]. To a considerable extent, the effectiveness of the processes of dissipation of electronic excitation energy in polymeric dye molecules depends on the composition of the solvate shell. In low-polarity organic solvents, cationic polymeric dyes may be present in the form of ions or a mixture of several types of ionic pairs [13, 14], the equilibrium distribution of the composition of which is shifted to the side of one of the ionic forms on change in the temperature, nature of the solvent, dye concentration, or change of the anion introduced into the solution of ionic and solvating additives [15]. It is shown in [16] that cationic polymeric dyes in blood serum are localized in the region with a low permittivity of the medium. Since in low-polarity media polymeric dyes can be present in the form of an equilibrium mixture of different ionic forms, this may exert a considerable influence on all of the photophysical properties of polymeric dyes in biological systems. In this work, we present the results of spectral-luminescent investigations that make it possible to answer the question as to the state of polymeric dye molecules in the culture of tumor cells of the HeLa strain.

Materials and Methods. As the object of investigation, we have selected the symmetrical cationic indotricarbocyanine dye TIKS [16]. Based on the cation of this dye, two compounds with the $\mathrm{Br}^{-}$and $\mathrm{BF}_{4}^{-}$anions have been

\footnotetext{
*To whom correspondence should be addressed.
}

A. N. Sevchenko Institute of Applied Physical Problems, Belarusian State University, 7 Kurchatov Str., Minsk, 220064, Belarus; e-mail: samtsov@bsu.by. Translated from Zhurnal Prikladnoi Spektroskopii, Vol. 71, No. 2, pp. 166172, March-April, 2004. Original article submitted October 10, 2003. 
synthesized (PD1 and PD2, respectively). Synthesis was done at the Laboratory of Spectroscopy of the A. N. Sevchenko Scientific-Research Institute of Applied Physical Problems.

For the investigations we used a monolayer of a culture of the HeLa tumor cells (planocellular cancer of the neck of the womb of a human being) grown in nutrient medium 199 with the addition of $10 \%$ blood serum of a cow fetus and $100 \mu \mathrm{g} / \mathrm{ml}$ of kanamycin. The culture of the HeLa cells was scattered into penicillin bottles with $2 \mathrm{ml}$ of a nutrient medium. Three days later, when the number of cells in the bottle reached a million, a solution of the test dye at a concentration of $2-20 \mu \mathrm{g} / \mathrm{ml}$ was introduced into the nutrient medium. The bottles, placed into an opaque package, were incubated in a thermostat at a temperature of $37^{\circ} \mathrm{C}$ for $2 \mathrm{~h}$, which corresponds to the maximum in the kinetics of accumulation of test dyes in cells [17]. Thereafter, the monolayer was washed free of the dye by a Hanks solution, dispersed by a $0.02 \%$ Versene solution, and was subjected to multiple pipetting until a homogeneous suspension of cells was formed. To prevent precipitation of the cells during measurements, the samples were agitated by a magnetic mixer. The number of cells was counted with the aid of a Goryaev chamber.

The corrected fluorescence and fluorescence excitation spectra were recorded by means of a Fluorolog spectrofluorimeter of the Spex Company. The absorption spectra were recorded using a PV 1251 A spectrophotometer of the Solar Company (Belarus) or a Specord M40 one (Germany). The kinetics of damping of the fluorescence of dyes was analyzed by the pulse spectrofluorimeter developed at the Laboratory of Spectroscopy of the Scientific-Research Institute of Applied Physical Problems [18]. The device is based on the scheme of time-correlated photon counting. The error in determining the fluorescence lifetime is $\Delta \tau= \pm 0.1 \mathrm{nsec}$, the error in determining the fluorescence polarization degree $\Delta P \leq \pm 4 \%$, and the relative error in determining the quantum yield of fluorescence $\left(\varphi_{\mathrm{fl}}\right)$ did not exceed $7 \%$. The accuracy in determining the halfwidth of the spectral bands was $\Delta\left(\Delta \lambda_{1 / 2}\right)= \pm 0.1 \mathrm{~nm}$ and that of the molecular extinction coefficient $\Delta \varepsilon= \pm 10^{4} \mathrm{M}^{-1} \cdot \mathrm{cm}^{-1}$. The luminescence characteristics of polymethine dyes depend greatly on the temperature of the solution; therefore, the samples were always thermostated.

Results and Discussion. Due to the fact that in cells the molecules of dyes may be present in both the water medium and organelles, we carried out investigations of the spectral properties of polymethine dyes in organic solvents, in a physiological salt solution, and directly in a suspension of HeLa cells. For both polymethine dyes investigated we observed identical changes in the spectral luminescent properties in going over from polar organic solvents to a physiological salt solution. In contrast to the spectra obtained in ethanol, the halfwidth of the fundamental absorption band of dyes increases up to $129 \mathrm{~nm}$ and two maxima comparable in intensity are manifested: a shortwave one at $\lambda_{1}=670 \mathrm{~nm}$ and a longwave one at $\lambda_{2}=706 \mathrm{~nm}$. An increase in the temperature of the solution or a decrease in the concentration leads to an increase in the intensity of absorption in the longwave maximum and its decrease in the shortwave one (Fig. 1). Moreover, the presence of an isobestic point in the spectra indicates the presence of two types of absorbing centers in the solutions. In the case of the physiological salt solution, the fluorescence spectra of dyes are shifted to the shortwave region as compared to organic solvents, whereas the quantum yield of fluorescence is approximately an order of magnitude smaller. When these samples are heated, the intensity of their fluorescence increases. It follows from the data obtained that dyes in a physiological salt solution in a range of concentrations from $10^{-7}$ to $10^{-3} \mathrm{M}$ are predominantly present in the form of associates.

The absorption spectra of the investigated dyes in the HeLa cells differ slightly. The maxima of the absorption bands are located at $\lambda=738 \mathrm{~nm}$ and the shapes of the spectra are almost identical. The halfwidth of the spectrum for PD1 is equal to $\Delta \lambda_{1 / 2}^{\mathrm{abs}}=60 \mathrm{~nm}$ and for PD2 $\Delta \lambda_{1 / 2}^{\mathrm{abs}}=56 \mathrm{~nm}$. When the dye is introduced into a nutrient medium at a concentration of $2-10 \mu \mathrm{g} / \mathrm{ml}$, its content in the cells varies within $4 \cdot 10^{-6}-2 \cdot 10^{-5} \mathrm{M}$. An increase in the concentration above $10 \mu \mathrm{g} / \mathrm{ml}$ leads to an increase in the halfwidth of the spectrum of PD in the cells, pointing to the formation of associates. However, such high (approaching the threshold of cytotoxicity) concentrations of dyes are of no interest to investigators. The quantum yield of the fluorescence of PD in cells has values which are close to the yield in solutions in ethanol and chlorous methylene, i.e., is more than an order of magnitude higher than in water. Based on these data, we may conclude that dyes introduced into cells at a concentration of $2-10 \mu \mathrm{g} / \mathrm{ml}$ are in a monomeric state. The positions of the maxima of the absorption bands of PD in the cells are close to those observed in the spectra of dyes in organic low-polarity solvents such as chlorous methylene and dichlorobenzene. Only in the case of PD in cells at the longwave edge of the fundamental band of absorption there is no shoulder, which in lowpolarity solvents is due to the presence of free ions of the PD molecules [14]. The halfwidth of the absorption spectra of dyes in the cells has values close to those in chlorous methylene. Thus, for PD1 in chlorous methylene $\Delta \lambda_{1 / 2}^{\text {abs }}=66$ 


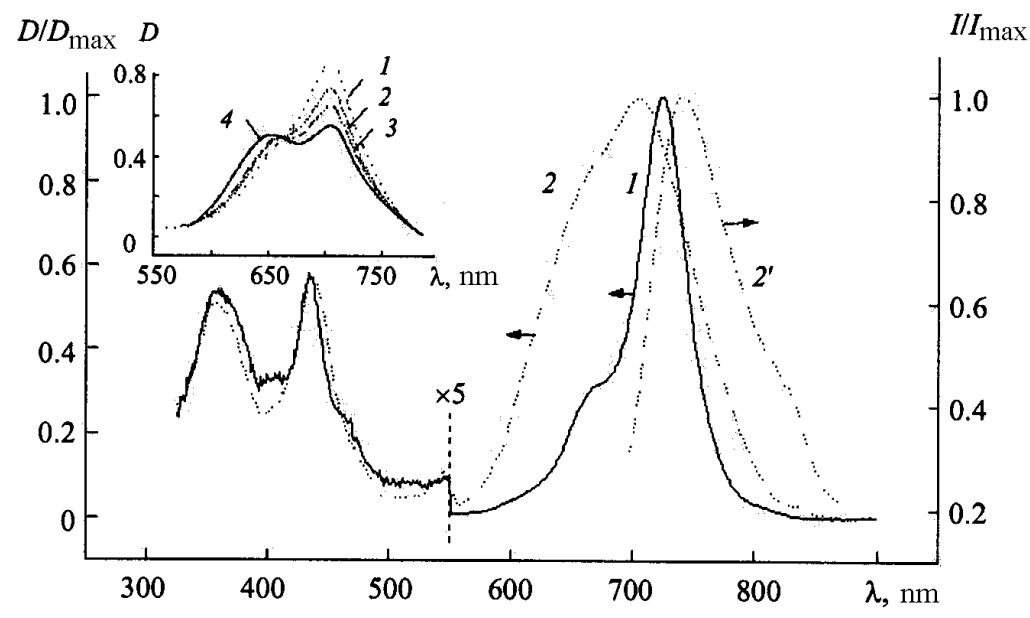

Fig. 1. Absorption $(1,2)$ and fluorescence $\left(2^{\prime}\right)$ spectra of the PD1 dye in ethanol (1) and physiological salt solution (2, 2'); the absorption spectra of PD1 in the physiological salt solution at $65(1), 35(2), 25$ (3), and $5.5^{\circ} \mathrm{C}(4)$ are shown in the inset.

$\mathrm{nm}$ and for PD2 $\Delta \lambda_{1 / 2}^{\mathrm{abs}}=55 \mathrm{~nm}$, i.e., for PD the halfwidth is $11 \mathrm{~nm}$ less. This difference in the halfwidth of the absorption bands of these dyes in low-polarity solvents is due to the formation of closer ion pairs in PD2 (because of the presence of $\mathrm{BF}_{4}^{-}$as an anion) as compared to PD1 [14]. The halfwidths for these very dyes in cells differ somewhat less (for PD2 $\Delta \lambda_{1 / 2}^{\text {abs }}$ is $4 \mathrm{~nm}$ smaller). The close position of the absorption spectra of the investigated compounds in the HeLa cells and in low-polarity solvents and also the same character of differences on change in the dye anion point to the fact that in the cells the molecules of dyes are localized in the region with a low permittivity and do not make contact with water.

The shape and position of the fluorescence spectra of the investigated compounds in HeLa do not change on excitation within the limits of the longwave absorption band. The halfwidth of the fluorescence bands for the dye PD1 is $\Delta \lambda_{1 / 2}^{\mathrm{fl}}=66 \mathrm{~nm}$ and for PD2 it is $6 \mathrm{~nm}$ less. These differences in the fluorescence spectra of dyes in the cells in going over from PD1 to PD2 are similar to the behavior in low-polarity organic solvents (Fig. 2). Thus, in the case of chlorous methylene the halfwidth of the spectrum of the PD2 dye is $\Delta \lambda_{1 / 2}^{\mathrm{fl}}=55 \mathrm{~nm}$. It is also smaller in comparison with PD1 (by $25 \mathrm{~nm}$ ). These results agree with notions about the low permittivity of the medium in which the investigated PD in cells are placed.

The degree of polarization of the fluorescence of PD in a suspension of HeLa cells at a temperature of $20^{\circ} \mathrm{C}$ is rather high $(\approx 36 \%)$. At the same time, in ethanol, where the lifetime of the molecules of dyes in an excited state is somewhat lower than in cells, this degree is equal to $24.9 \%$. The high polarization degree of the fluorescence of the investigated compounds in the cells points to the fact that in this system the molecules of the dyes during their lifetime in an excited state have no time to change their orientation. Taking these data into account, we may conclude that in cells the dyes are bound with the cell structures. The fact that for a PD in the cells the polarization degree of fluorescence has a lower value in comparison with the blood serum $(P=46.3 \%$ [16] $)$ is rather due to the optical inhomogeneity of the suspension of cells and to the effect of radiation scattering.

Taking into account the differences in the spectral characteristics of the PD1 dye in comparison with PD2, which in low-polarity media is due to the formation of closer ion pairs for PD2 [14], we may assume the presence of the PD1 dye molecules also in cells at least in two forms: as contact and solvately separated ion pairs or free ions. We have failed to detect any signs of the existence of several forms of dyes in such a system from the fluorescence spectra on excitation within the limits of the fundamental absorption band and from the fluorescence excitation spectra depending on the recording wavelength in the longwave region. As shown in [14], the formation of ion pairs is manifested more distinctly in analyzing the spectral-luminescent properties in the shortwave region of the absorption of dyes. Unfortunately, it is not possible to investigate the absorption spectra and the polarization spectra of dyes in cells 

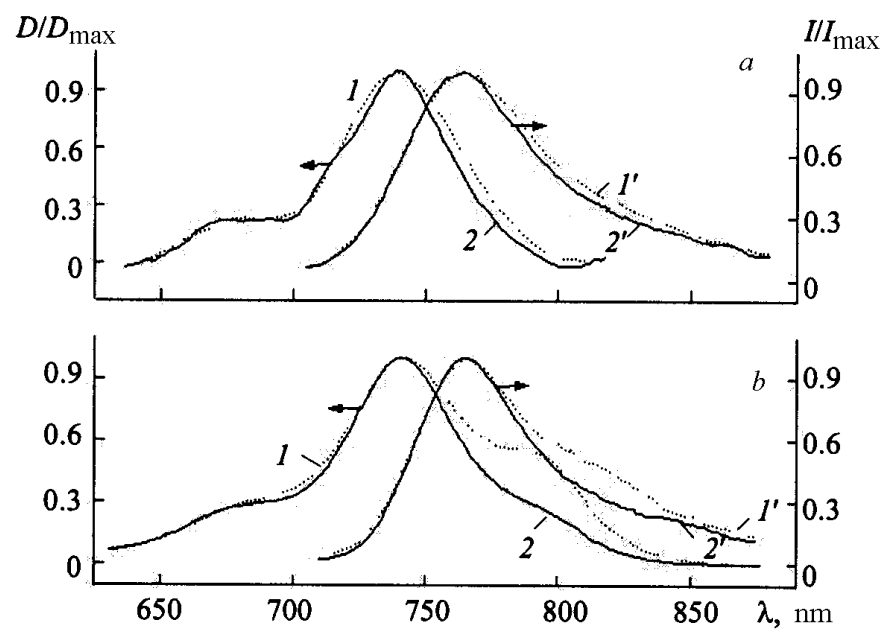

Fig. 2. Absorption $(1,2)$ and fluorescence $\left(1^{\prime}, 2^{\prime}\right)$ spectra of PD1 $\left(1,1^{\prime}\right)$ and PD2 $\left(2,2^{\prime}\right)$ in a culture of HeLa cells (a) and in DCB (b); $\lambda_{\text {exc }}=690 \mathrm{~nm}$.

in a spectral region more shortwave than $550 \mathrm{~nm}$. This is due to the fact that in the shortwave region the absorption coefficient of the investigated compounds is approximately an order of magnitude lower than the fundamental band and also to the more considerable manifestation of the scattering of light of the visible range in a suspension of cells. However, the noted facts have not impeded recording and analysis of the fluorescence excitation spectra of dyes in the 300-550-nm region. Comparison of these spectra for PD1 in recording on the longwave edge of the emission spectrum $\left(\lambda_{\text {rec }}=805 \mathrm{~nm}\right)$ with the spectra recorded on the shortwave edge $\left(\lambda_{\text {rec }}=750 \mathrm{~nm}\right)$ has made it possible to reveal the following differences. In recording at $805 \mathrm{~nm}$, a higher intensity in the 440-nm region is observed in the spectrum, whereas at $\lambda_{\text {rec }}=750 \mathrm{~nm}$ an increase in the relative contribution to the band spectrum at $410 \mathrm{~nm}$ is observed. In lowpolarity solvents, such as chlorous methylene and dichlorobenzene, singular "deformations" occur in the spectra of fluorescence excitation with the recording wavelength (Fig. 3). Thus, when recording on the shortwave edge of the fluorescence band of PD in the excitation spectrum the bands are narrower, the peak at $\lambda=410 \mathrm{~nm}$ almost does not manifest itself, and the band at $441 \mathrm{~nm}$ has a large relative intensity, whereas in recording on the longwave edge of the fluorescence spectrum the contribution of the band at $410 \mathrm{~nm}$ increases. The shape of the fluorescence excitation spectrum of PD1 in the cells is closer to the spectra of PD in low-polarity solvents that were recorded on the shortwave edge of the fluorescence spectrum, i.e., in the maximum corresponding to the contact ion pairs [14]. In the fluorescence spectrum of PD1, in the organic solvents used, in transition from excitation at $\lambda_{\text {exc }}=407 \mathrm{~nm}$ to $440 \mathrm{~nm}$ the intensity increases in the shortwave maximum, and a hypsochromic shift of the fluorescence maximum by $3 \mathrm{~nm}$ is observed in the cells. In the fluorescence spectra of PD in cells, in contrast to organic solvents, two bands are not manifested on such excitation. At the same time, changes in the fluorescence excitation spectra of the PD1 dye depending on the recording wavelength in combination with the hypsochromic shift of its fluorescence spectrum from the excitation wavelength indicate the presence of several emitting centers in the cells. For the PD2 dye, no changes in the fluorescence spectra have been detected in the cells depending on the excitation wavelength and in the fluorescence excitation spectra depending on the recording wavelength. In low-polarity solvents, spectral changes for this dye with the recording wavelength and excitations are also not so considerable in comparison with PD1 [14]. The spectral "deformations" observed in low-polarity solvents for PD are due to the presence of contact ion pairs and free ions of dyes in the solutions. In the HeLa cells, similar differences are observed in the spectral characteristics of PD1, but these differences are less appreciable.

The characteristics of fluorescence for the PD1 and PD2 dyes in the cells (quantum yield, lifetime, and polarization degree of fluorescence) virtually coincide (see Table 1). For PD the quantum yield and lifetime of fluorescence are greatly determined by the viscosity of the solvents [14]; therefore the obtained values for PD in the cells, when compared with the data for organic solvents, appear to be somewhat unexpected. The investigations of polarization and spectra point to the high viscosity and low permittivity of the medium in which the molecules of PD in the 


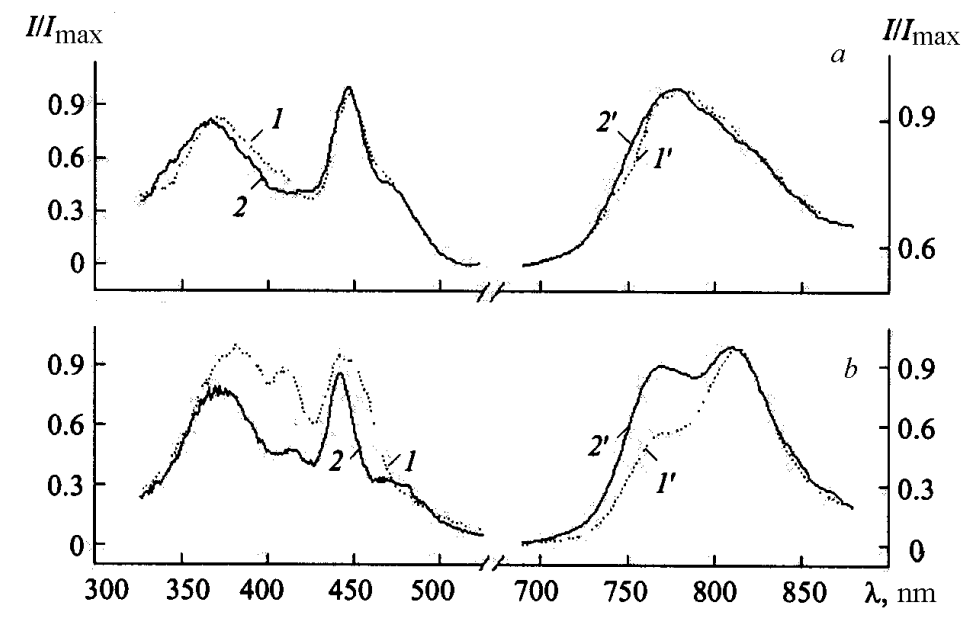

Fig. 3. Fluorescence excitation $(1,2)$ and fluorescence $\left(1^{\prime}, 2^{\prime}\right)$ spectra of PD1: a) in a culture of HeLa cells at $\lambda_{\text {rec }}=805$ (1) and $750 \mathrm{~nm}(2), \lambda_{\text {exc }}=406$ (1') and $\left.445\left(2^{\prime}\right) ; \mathrm{b}\right)$ in dichlorobenzene at $\lambda_{\text {rec }}=812$ (1) and $764 \mathrm{~nm}(2), \lambda_{\text {exc }}=$ $409\left(1^{\prime}\right)$ and $441 \mathrm{~nm}\left(2^{\prime}\right)$.

cells are located. On the other hand, the quantum yield and lifetime of the fluorescence of dyes in the cells are close to the values obtained in a low-viscosity chlorous methylene $(0.435 \mathrm{cP})$ and smaller than in dichlorobenzene with a viscosity of $1.2 \mathrm{cP}$. This relationship between the fluorescence parameters in the media considered is probably due to the fact that in the cells the dyes are present predominantly in the form of contact ion pairs for which a shorter lifetime and smaller fluorescence quantum yield are typical in comparison with free ions [14]. For the PD1 dye in cancer cells, just as in low-polarity organic solvents, the presence of a certain fraction of free cations is manifested. For the PD2 dye the presence of only one type of fluorescing centers (contact ion pairs) is revealed in the biosystem, which is a consequence of the stronger cation-anion interaction in the molecule of this compound in comparison with the PD1.

To elucidate the reasons for the presence of PD in the cells predominantly in the form of contact ion pairs, we investigated the influence of the additional introduction of salts on the spectral-luminescent properties of dyes in low-polarity solvents. This trend in the investigations is attributable to the fact that usually the cell structures contain a rather large number of ions, such as $\mathrm{Cl}^{-}(0.117 \mathrm{M}), \mathrm{K}^{+}(0.153 \mathrm{M})$, etc. [1], whereas the presence of salts in lowpolarity media may shift the equilibrium of the ion forms of dyes to the side of one of them $[13,14,16]$.

As additives we selected organic salts dissolved in low-polarity media: trimethyl benzyl ammonium chloride and tetrabutyl ammonium bromide. While the choice of the former was attributable to the high enough concentration of the $\mathrm{Cl}^{-}$ions in the cells, the choice of the latter salt was due to the fact that it had the same anion as the PD1 dye, and the salt was taken to elucidate the possible effect of the process of substitution of the $\mathrm{Br}^{-}$anion in the dye molecules by the $\mathrm{Cl}^{-}$ions on introduction of considerable concentrations of the additional salt. As a result of the investigations, it has been found that the addition of any of these salts causes identical "deformation" of the absorption spectra of the PD1 and PD2 dyes to the side of an increase in the intensity at the maximum of the fundamental band and a decrease in the absorption in the region of the longwave shoulder. This points to the increase in the fraction of contact ion pairs and decrease in free cations. In the absorption spectra of the PD1 (Fig. 4), on addition of even $10^{-5} \mathrm{M}$ of salt, a decrease in the relative intensity of the longwave shoulder is observed, whereas at a concentration of salts at $10^{-2} \mathrm{M}$ the shoulder entirely disappears, and simultaneously the halfwidth of the fundamental absorption band decreases. In this case, the molar absorption coefficient at the maximum of this band increases by more than a factor of 1.5. The relative contribution of the shortwave absorption bands to the spectrum of PD (300-500 nm) decreases on the whole on introduction of a salt. As shown in [14], this change in the relationship between the intensities in shortwave bands and in the main maximum usually occurs in transition to the PD present in a solution in the form of contact ion pairs. Changes in the absorption spectra on introduction of a salt are accompanied by a decrease 
TABLE 1. Spectral-Luminescent Characteristics of Dyes in Various Media

\begin{tabular}{|c|c|c|c|c|c|c|c|c|c||}
\hline \hline Medium & FR & Ethanol & \multicolumn{2}{|c|}{ CM } & \multicolumn{2}{|c|}{ DCB } & DCB + salt & \multicolumn{2}{c|}{ HeLa } \\
\hline Dye & PD1, PD2 & PD1, PD2 & PD1 & PD2 & PD1 & PD2 & PD1 & PD1 & PD2 \\
\hline$\lambda_{\max }^{\text {abs }, \mathrm{nm}}$ & 704 & 724 & 734 & 735 & 742 & 740 & 742 & 738 & 739 \\
$\lambda_{\max }^{\mathrm{fl}}, \mathrm{nm}$ & 741 & 750 & 760 & 761 & 766 & 765 & 768 & 766 & 765 \\
$\Delta \lambda_{1 / 2}^{\mathrm{bs}}, \mathrm{nm}$ & 129 & 50 & 66 & 55 & 83 & 55 & 50 & 60 & 65 \\
$\Delta \lambda_{1}^{\mathrm{fl}}, \mathrm{nm}$ & 102 & 52 & 80 & 55 & 66 & 54 & 48 & 66 & 60 \\
$\varphi^{\mathrm{fl}}\left(20^{\circ} \mathrm{C}\right)$ & 0.02 & 0.22 & 0.20 & 0.18 & 0.45 & 0.38 & 0.39 & 0.23 & 0.22 \\
$P, \%\left(15^{\circ} \mathrm{C}\right)$ & - & 24.9 & 8.7 & 9.8 & 16.0 & 17.5 & 21.0 & 36.2 & 36.4 \\
$\tau, \mathrm{nsec}\left(20^{\circ} \mathrm{C}\right)$ & 0.5 & 1.1 & 1.3 & 1.2 & 1.9 & 1.6 & 1.8 & 1.4 & 1.4 \\
\hline
\end{tabular}

Note: $\lambda_{\max }^{\mathrm{fl}}$, wavelength at the fluorescence maximum; $\lambda_{\max }^{\mathrm{abs}}$, wavelength at the absorption maximum; $\varphi^{\mathrm{fl}}$, quantum yield of fluorescence $\left(\lambda_{\text {exc }}=690 \mathrm{~nm}\right) ; P$, degree of fluorescence polarization $\left(\lambda_{\text {exc }}=\lambda_{\max }^{\text {abs }}\right.$ and $\left.\lambda_{\text {rec }}=\lambda_{\max }^{\mathrm{fl}}\right)$; $\tau$, lifetime of molecules in the first excited singlet state (at the maximum of the fluorescence spectrum).

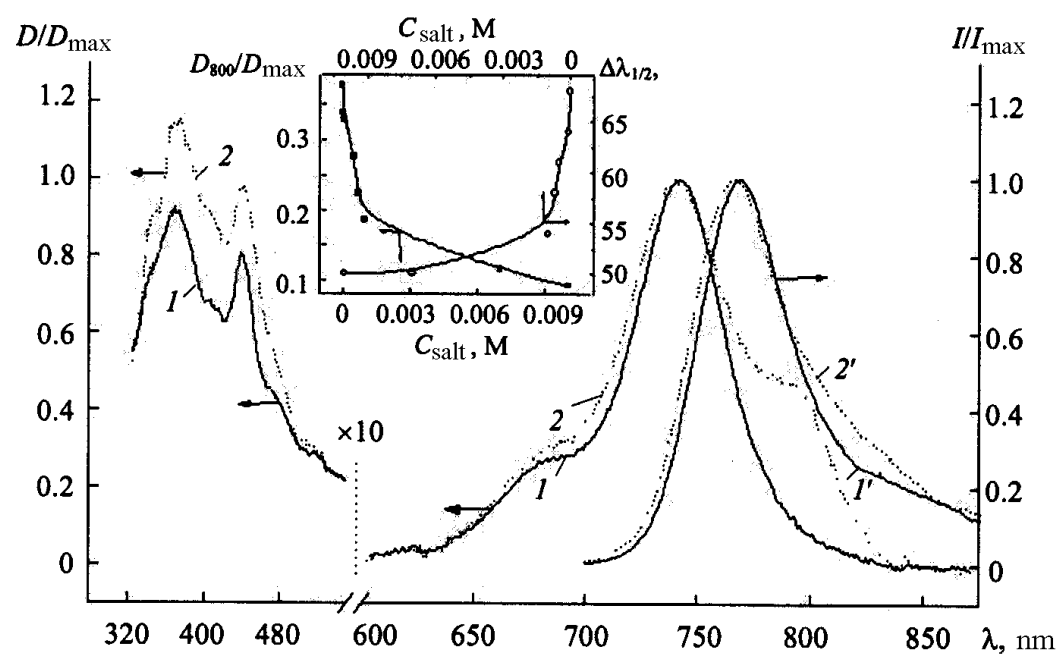

Fig. 4. Absorption $(1,2)$ and fluorescence $\left(1^{\prime}, 2^{\prime}\right)$ spectra of PD1 in DCB on introduction of tetrabutyl ammonium bromide in a concentration of $0\left(2,2^{\prime}\right)$ and $10^{-2} \mathrm{M}\left(1,1^{\prime}\right), \lambda_{\text {exc }}=690 \mathrm{~nm}$; the dependence of the absorption-spectrum halfwidth and the relative optical density of the solution of PD1 in DCB at $\lambda=800 \mathrm{~nm}$ on salt concentration.

in the quantum yield and lifetime of the fluorescence of PD1. The values of these parameters of the fluorescence of the PD1 approach those of the PD2. In comparing the luminescence characteristics of the compounds investigated, the strengthening of the cation-anion interactions for PD2 in comparison with PD1 should be taken into account [14] as well as the formation of closer ion pairs which have lower $\varphi^{\mathrm{fl}}$ and $\tau$ as against free cations $[14,19]$. For the PD2 dye in dichlorobenzene the increase in the region of the longwave edge of the fundamental absorption band virtually disappears even on introduction of $10^{-5} \mathrm{M}$ of salt. Here, we have not managed to detect any changes in the fluorescence characteristics of PD2 on introduction of salts. The data obtained point to the fact that introduction of tetrabutyl ammonium bromide and trimethyl benzyl ammonium chloride in chlorous methylene and dichlorobenzene shifts the equilibrium to the side of the increasing fraction of contact ion pairs of the investigated PD without substituting their 
anions. Based on the data obtained, it can be concluded that the shift of the ionic equilibrium for PD in the cells to the side of contact ion pairs in comparison with low-polarity organic solvents is a consequence of the rather high concentration of ions of salts in the biosystem, which prevents division of the dye molecules into free ions.

Conclusions. It has been established that in HeLa cells the investigated PD are predominantly present in the form of contact ion pairs; the PD1 dye manifests the presence of a certain fraction of free cations or solvately divided ion pairs. The state of this equilibrium is considerably influenced by the nature of the dye anion and also the concentration of free ions in the system.

This work was carried out with support from INTAS and from the Belarusian Republic Basic Research Foundation.

\section{REFERENCES}

1. J. Hoffman and P. Laris, J. Physiol., 239, 519-524 (1974).

2. P. J. Sims, A. S. Waggoner, C.-H. Wang, and J. F. Hoffman, Biochemistry, 13, 3315-3320 (1974).

3. K. Maruszewski, A. Sidorowicz, A. Pola, and W. Strek, J. Mol. Struct., 444, 141-153 (1998).

4. M. Yu. Anikovskii, A. S. Tatikolov, L. A. Shvedova, and V. A. Kuz'min, Izv. Ross. Akad. Nauk, Ser. Khim., No. 7, 1134-1137 (2001).

5. A. R. Oseroff, G. Ara, D. Ohuoha, et al., Photochem. Photobiol., 46, 83-96 (1987).

6. G. S. Lipshutz, D. J. Castro, R. E. Saxton, et al., Laryngoscope, 104, 996-1002 (1994).

7. D. A. Bellnier, W. R. Potter, A. Lurine, et al., Photochem. Photobiol., 62, 896-905 (1995).

8. E. S. Voropai, M. P. Samtsov, A. P. Lugovskii, et al., Vestn. Bel. Gos. Univ., Ser. 1, Fizika, Matematika, Informatika, No. 3, 23-27 (1996).

9. E. S. Voropai (Voropay), M. P. Samtsov, A. P. Lugovsky, et al., Exp. Oncol., 19, 56-60 (1997).

10. E. Delaey, F. Laar, D. Vos, et al., J. Photochem. Photobiol. B, 55, 27-36 (2000).

11. E. S. Voropai, M. P. Samtsov, V. N. Chalov, and É. A. Zhavrid, Zh. Prikl. Spektrosk., 68, 359-362 (2001).

12. E. S. Voropai (Voropay), M. P. Samtsov, A. P. Lugovsky, E. N. Aleksandrova, V. N. Chalov, E. A. Zhavrid, and Yu. P. Istomin, Proc. SPIE, 4749, 221-227 (2002).

13. E. S. Voropai, M. P. Samtsov, K. N. Kaplevskii, and A. A. Lugovskii, Vestn. Bel. Gos. Univ., Ser. 1, Fizika, Matematika, Informatika, No. 1, 7-14 (2003).

14. E. S. Voropai, M. P. Samtsov, and K. N. Kaplevskii, Zh. Prikl. Spektrosk., 70, 635-641 (2003).

15. V. I. Avdeeva and M. A. Al'perovich, Usp. Nauch. Fotogr., 22, 84-90 (1984).

16. E. S. Voropai, M. P. Samtsov, K. N. Kaplevskii, et al., Vestn. Bel. Gos. Univ., Ser. 1, Fizika, Matematika, Informatika, No. 2, 28-30 (2000).

17. É. A. Zhavrid, Yu. P. Istomin, E. N. Aleksandrova, V. N. Chalov, E. S. Voropai, M. P. Samtsov, and A. P. Lugovskii, in: Urgent Problems of Oncology and Medicinal Radiology [in Russian], Collection of Papers, Minsk (2001), pp. 357-364.

18. E. S. Voropai, M. P. Samtsov, K. N. Kaplevskii, A. E. Rad'ko, and K. A. Shevchenko, Vestn. Bel. Gos. Univ., Ser. 1, Fizika, Matematika, Informatika No. 3, 7-13 (2002).

19. A. A. Ishchenko, Structure and Spectral Luminescence Properties of Polymethine Dyes [in Russian], Kiev (1994). 